\title{
acceso a los nuevos muelles en el puerto de Pasajes E SPA Ã A
}

CARLOS MARTINEZ CEBOLLA, Dr. ingeniero

$562-99$

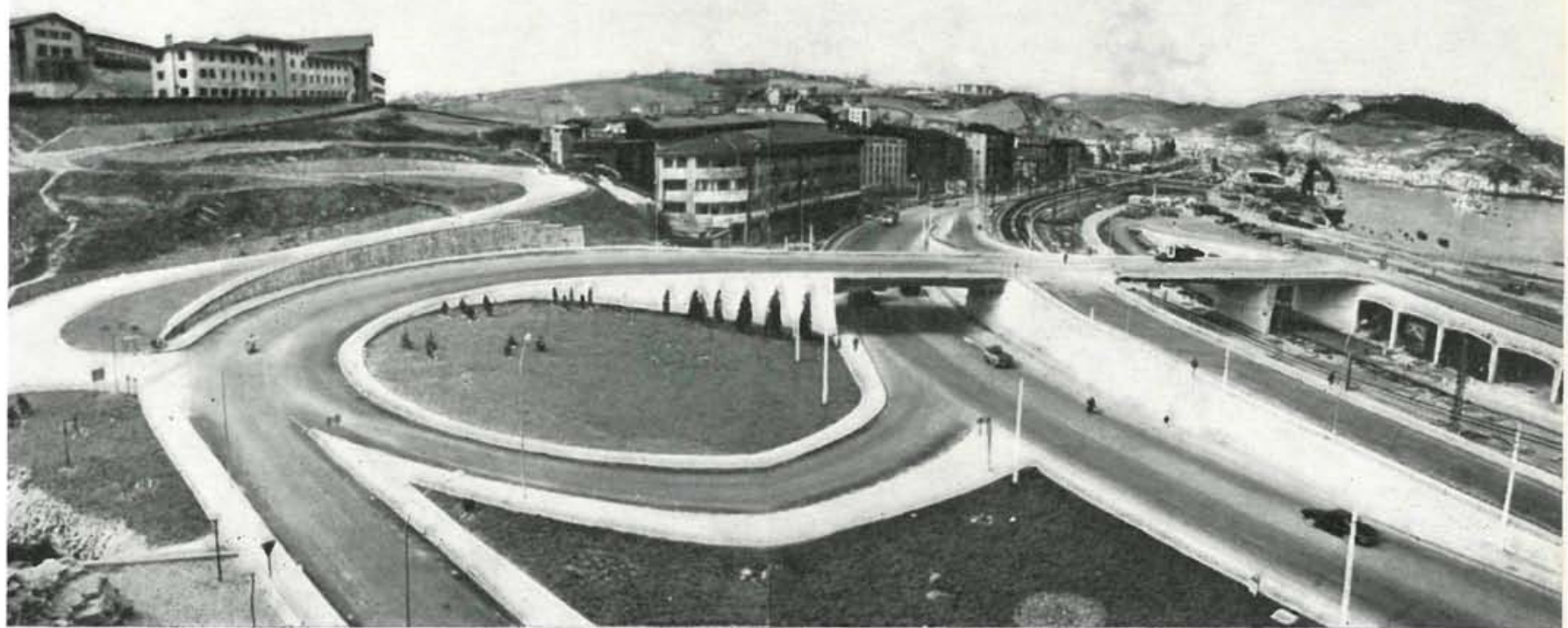

simopsis

En el presente artículo se describe la obra de los accesos a los Nuevos Muelles en Pasajes. Estos accesos tienen por objeto permitir la entrada y salida de vehículos a los muelles por encima de las vías de la Renfe y del Puerto y, además, sin producir ninguarios del Puerto y por en la carretera nacional N-1 de Madrid a Irún. Su estética y funcionalidad será apreciada por los motivo principal del artículo ha sido la descripción de la solución de pretensado que se ha dado a uno de los puentes. Es una de las primeras obras ejecutadas en Espana de este tipo, aun cuando, logicamente y dentro de unos años será un tipo de obra corriente, precisamente por la gran necesidad que hay de ellas. La obra fue inaugurada por el Excmo. Sr. Ministro

2

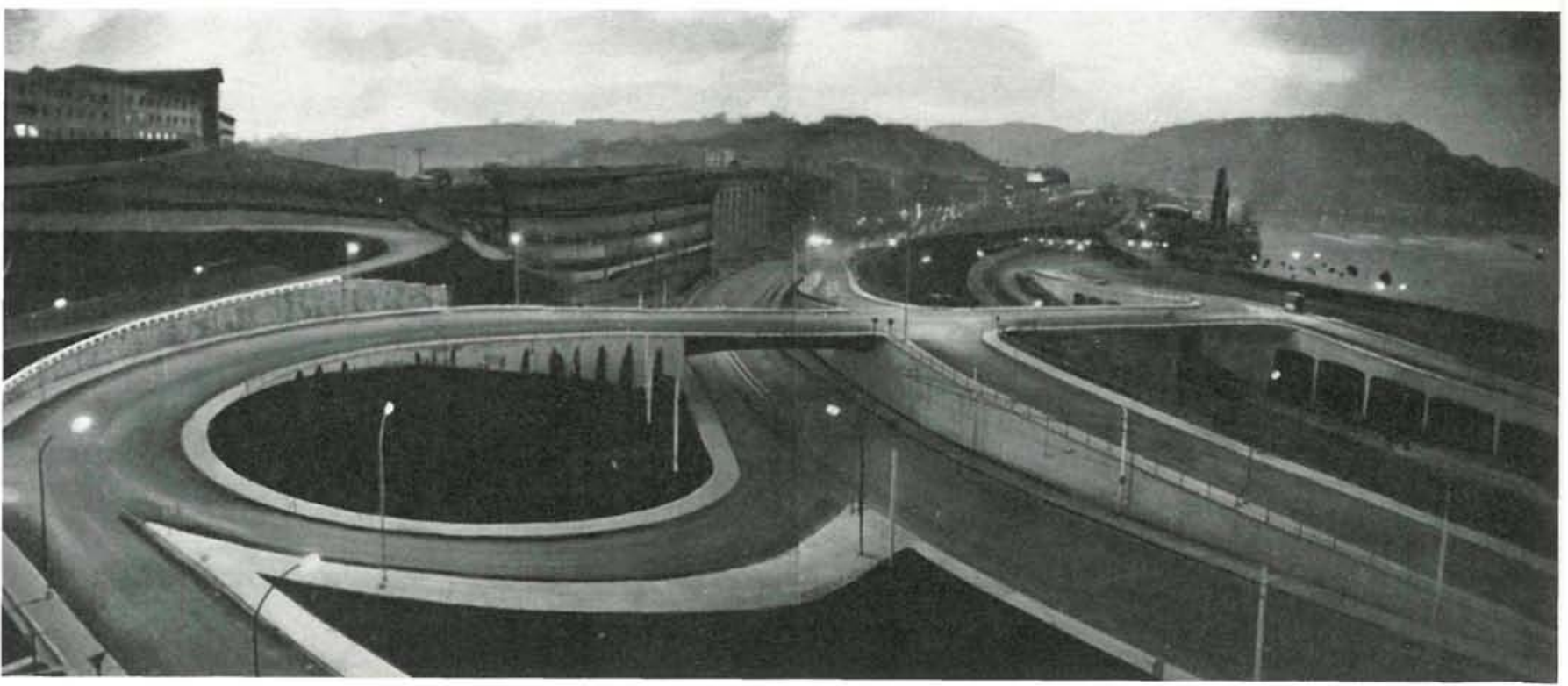




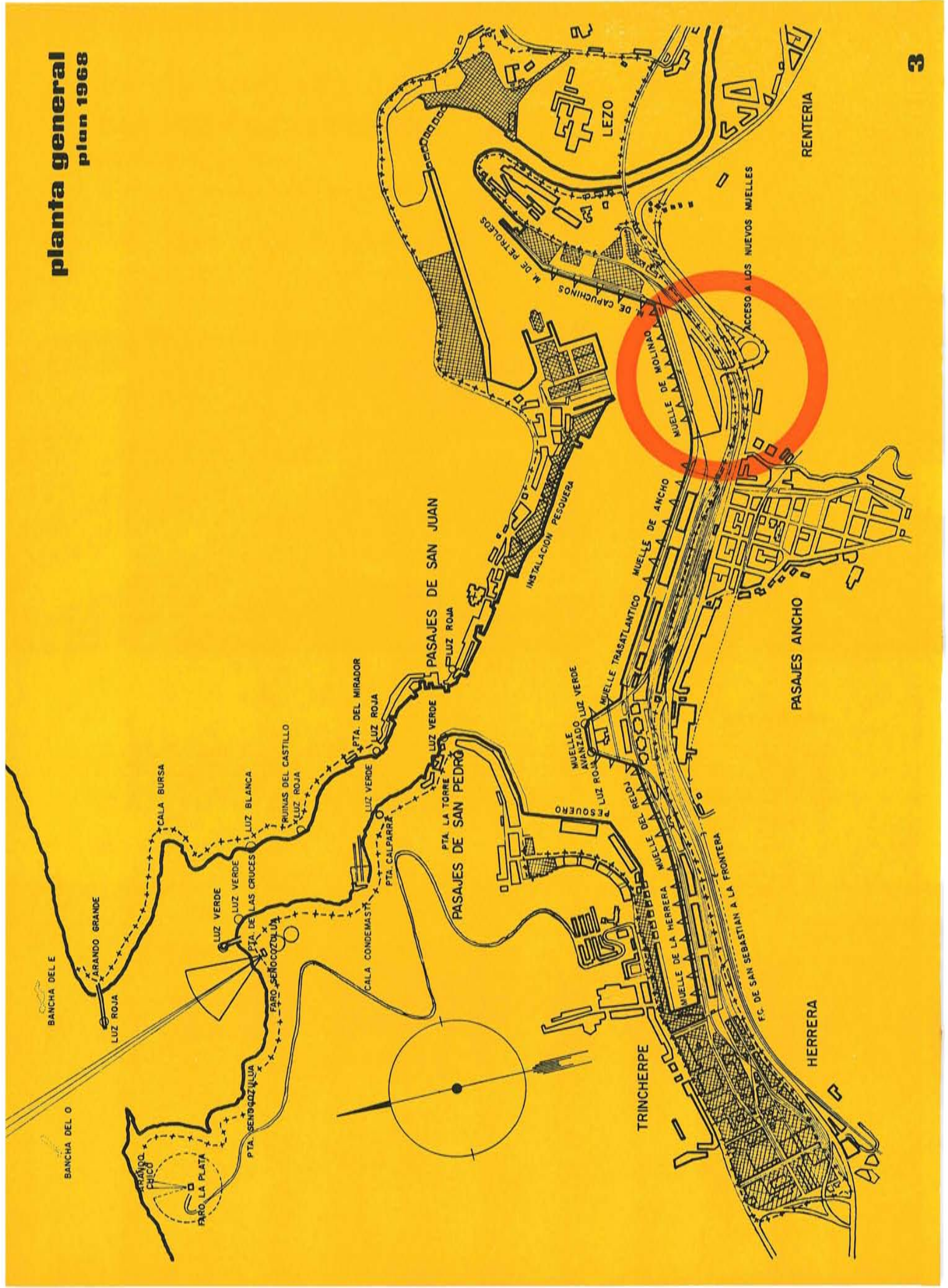




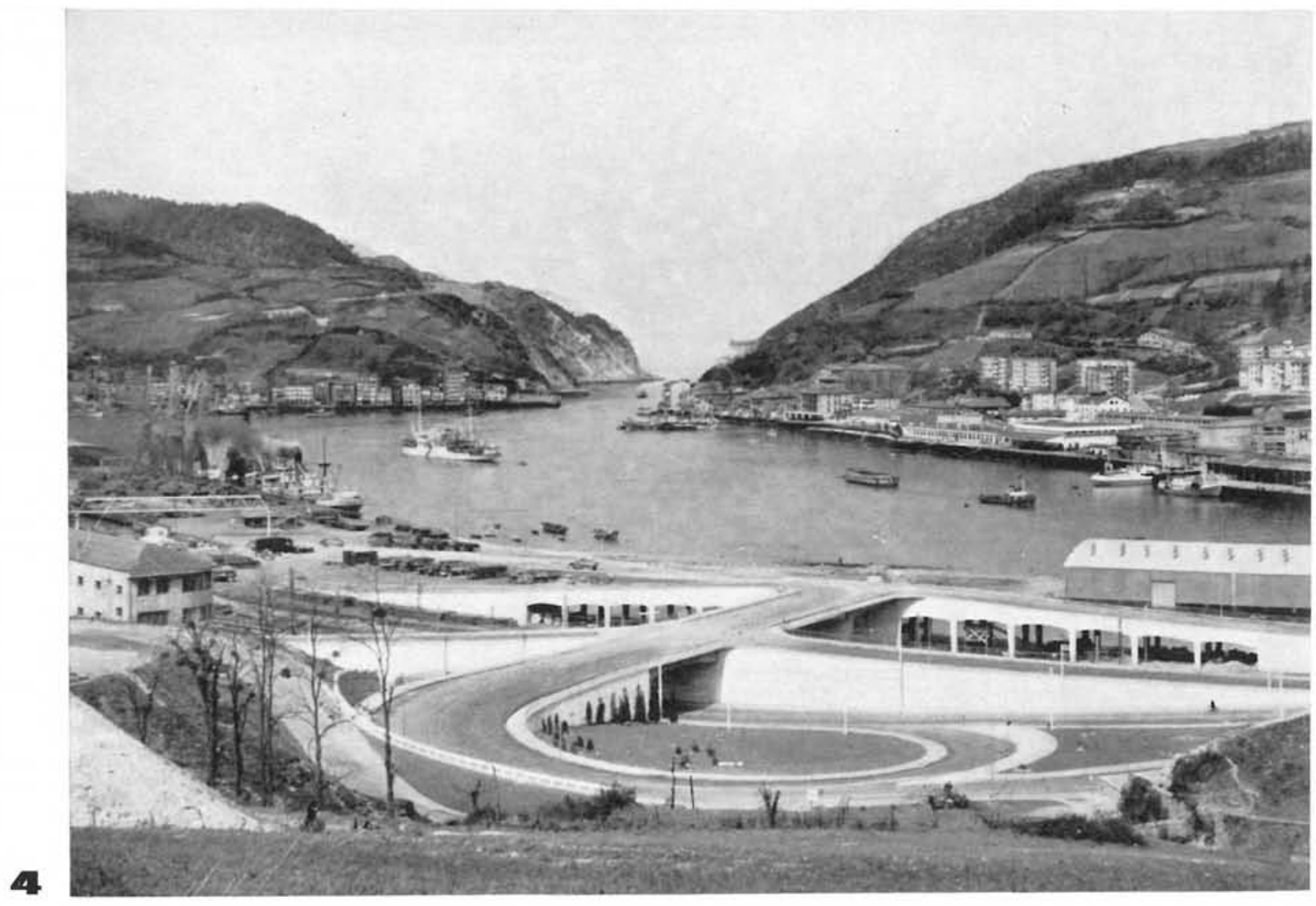

\section{Objeto ale Ia obra}

El fin de la obra de accesos a los Nuevos Muelles del Puerto, es el de permitir la entrada y salida de vehículos al mismo sin producir en ningún momento cortes de circulación en la carretera general de Madrid a Irún. Por otra parte, la incorporación a los muelles ha de hacerse necesariamente pasando por encima de las vías de RENFE y de las vías ferroviarias propias del Puerto para evitar los pasos a nivel, incompatibles con la seguridad del tráfico y la explotación portuaria en una zona de densidad de circulación (tanto de carretera como ferroviaria) $\tan$ elevada.

Aun cuando esta obra por su emplazamiento está especialmente indicada para dar servicio a las cuatro alineaciones de los Nuevos Muelles en el Puerto de Pasajes, por su importancia y comodidad de uso servirá también para la entrada y salida del tráfico de otras zonas portuarias, ya que compensará a los conductores la mayor seguridad en la incorporación a los muelles a pesar de un recorrido más largo. Incluso en un futuro, cuando los muelles de la zona de Lezo sean una realidad, los accesos que describimos darán servicio también a esa zona, a través de un puente, sobre el río Oyarzun, que se emplazará junto al actual del ferrocarril Madrid-Irún. 
Para juzgar sobre la necesidad de no producir cortes en la carretera, recordamos que la carretera nacional N-1 de Madrid a Irún, en la zona de Pasajes viene a tener una intensidad media diaria de unos 20.000 vehículos, circulando en una anchura de calzada de $12 \mathrm{~m}$, es decir, cuatro circulaciones algo escasas, y en la que se está llegando a una saturación en todos los sentidos. Para descongestionarla, por la Dirección General de Carreteras se han redactado los proyectos de variante para supresión de la travesía de San Sebastián y de autopista Bilbao a Behobia, obras que se complementan y que constituyen la única solución al grave problema que Guipúzcoa tiene planteado.

En cuanto al tráfico del Puerto de Pasajes, la cifra total a la que se llegó en el año 1965, incluyendo pesca y avituallamiento, ha sido la de $2.600 .000 \mathrm{t}$, con un total de 3.000 buques entrados durante el año de más de $100 \mathrm{t}$ de registro bruto. De este tonelaje total, parte se bombea a través de instalaciones especiales, como es el caso de los combustibles líquidos. El resto, o llega o sale del Puerto por camión o por vagón. Concretando en la parte que afecta a la carretera, en el año 1965 se cargaron o descargaron 130.000 camiones, con un total de 1.320 .000 t de mercancías, además de las $80.800 \mathrm{t}$ anuales de pesca, que salen íntegramente en camión. En los últimos diez años hemos visto duplicarse el tráfico comercial y es de esperar esta misma progresión en los próximos diez años venideros, por la sencilla razón de que Pasajes es el puerto natural de Guipúzcoa y Navarra y son éstas dos provincias que han experimentado un extraordinario desarrollo económico y social durante los últimos años. Recordamos que el Puerto de Pasajes ha sido uno de los cuatro elegidos por la Dirección General de Puertos para su financiación parcial con fondos procedentes del Banco Mundial, por la rentabilidad de las inversiones programadas en este Puerto para el año 1968. En la figura 3 aparece la planta general del Puerto con las obras correspondientes al año 1968 y la situación de la obra de los accesos, que ha dado origen a este artículo.

\section{Descripción sucinte de rumpers y puentes}

Para los vehículos que proceden de San Sebastián, el primer elemento de la obra que se encuentra es el bucle viario que sirve para la incorporación al puerto y a la vez de salida de tráfico con dirección a Irún. En planta el trazado es muy suave, pues el radio del eje de la calzada es de $31 \mathrm{~m}$. La anchura de la explanación es de $18 \mathrm{~m}$, de ellos $14 \mathrm{~m}$ destinados a calzada y el resto a dos aceras laterales de $2 \mathrm{~m}$ de anchura cada una de ellas. La pendiente longitudinal es del 4,26 por 100. Al final de las obras se estrecharon las uniones o contactos del bucle y rampas con la carretera general, de acuerdo con unas obras de mejora que se están llevando a cabo por la Dirección General de Carreteras en la actualidad. En la figura 6 puede verse la planta general de la obra antes de hacer los estrechamientos citados.

Circulando hacia los muelles sigue después el paso superior sobre la carretera, obra que se realizó en la primera fase, ya que el trazado de la carretera general era distinto y se mejoró pasando bajo nuestro paso una vez que se realizó éste. El paso sobre la carretera se resolvió con una estructura perfectamente empotrada en los muros estribos y constituida por unas vigas solidarizadas con tableros superior e inferior, es decir, una sección en cajón. El trasdós de las vigas es horizontal y el intradós parabólico con $90 \mathrm{~cm}$ de flecha. Bajo el paso queda un gálibo libre de $6 \mathrm{~m}$, que permite la circulación muy holgada de todo tipo de vehículos por debajo del mismo.

Seguidamente tenemos el paso superior sobre las vías de RENFE y del Puerto, que es la parte más importante de la obra y cuya descripción será objeto de apartado diferente en este mismo artículo.

A continuación nos encontramos con las dos rampas simétricas de entrada y salida al Puerto y que van desde la rasante de los dos puentes a la rasante de los muelles. La longitud total de cada brazo es de $140 \mathrm{~m}$; su anchura, de $12 \mathrm{~m}$ (10 m de calzada y dos aceras de $1 \mathrm{~m})$, y la pendiente, del 7,54 por 100. Estructuralmente hay tres cuerpos bien definidos, y cuya función describimos. El cuerpo central es un edificio de planta baja y dos plantas y en el cual se instalarán oficinas dependientes de la Junta de Obras. A cada lado de este cuerpo se encuentran dos estructuras porticadas, formadas por seis vanos, de $9 \mathrm{~m}$ de luz cada uno, en cada una de las rampas y en cuyo interior se guardará la maquinaria de la Junta, de la Sociedad Auxiliar del Puerto y de los estibadores. Finalmente, donde la altura libre no permitía el aprovechamiento se han proyectado los laterales de las rampas a base de muros. La cimentación de los pórticos y del cuerpo central se hace directamente sobre la roca a través de pilotaje in situ de $630 \mathrm{~mm}$ de diámetro y con una longitud aproximada de unos 22 metros. 


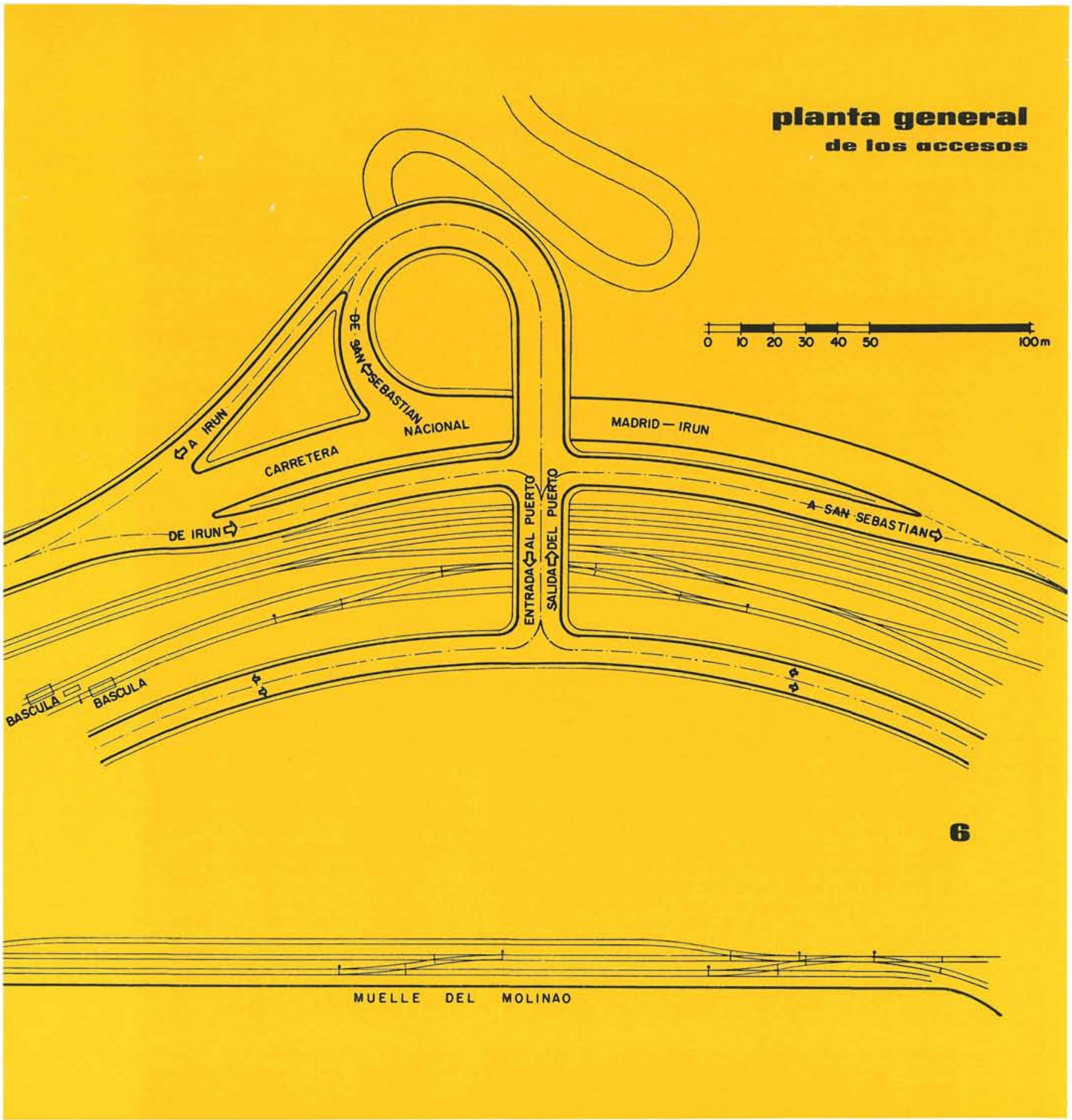

Por último, entre la carretera general y las vías de RENFE se han ejecutado dos rampas para completar la posibilidad de realizar todos los movimientos sin obstaculizar el tráfico de la carretera: Una de las rampas es para la entrada de vehículos procedentes de Irún, con el 4,96 por 100 de pendiente, y la segunda rampa es de salida hacia San Sebastián, con el 8,68 por 100. El relleno de las rampas está sostenido por muros laterales en L, débilmente armados y con una gran base en el apoyo del terreno natural, pues por la profundidad a que se encuentra la roca no podía pensarse en cimentar sobre ella. Decidimos el empleo del muro en L, en lugar de los clásicos de fábrica, para disminuir los asientos al conseguir una mayor superficie de apoyo. 


\section{Paso superior sobre la Remfe. Su estructura}

Recordamos que bajo este paso se encuentran las vías de circulación de la RENFE de Madrid a Irún (línea electrificada), así como las vías de maniobra colindantes con ellas. Paralelamente a la playa de vías de RENFE se encuentran las vías del Puerto, cuyo objeto es el de incorporar los vagones o el de clasificar los mismos. Por encima de todas ellas debe el puente salvar la luz total de $45 \mathrm{~m}$, que es la separación entre las rampas del lado del puerto y las del lado de la carretera.

La primera condición que debe cumplir el puente, es que su ejecución ha de ser posible sin producir ninguna perturbación en el tráfico ferroviario, pues no cabe hablar de paralizaciones en la vía ni tampoco pensar en la desviación del tráfico de trenes por vías provisionales, ya que hay la imposibilidad de tenderlas.

Esta condición enunciada nos lleva de la mano a soluciones prefabricadas, puesto que el hormigonado in situ de las vigas, aparte del peligro que representaría la proximidad de las líneas de alimentación eléctrica, nos produciría en el ferrocarril los trastornos que intentamos evitar por todos los medios.

La prefabricación en nuestro caso solamente tiene un inconveniente, y es la elevada potencia de los medios auxiliares para la colocación de las vigas en su posición definitiva. Y presenta una gran ventaja, como es el control que existe en la fabricación de las vigas y las elevadas resistencias que se encuentran. Así, pues, hemos llegado a la elección de vigas prefabricadas con el menor peso posible, y esto no es factible más que en las soluciones hiperestáticas, ya que el hiperestatismo, a causa de una más favorable distribución de momentos, permite reducir cantos y dimensiones.

Puede parecer en principio que el hiperestatismo es incompatible con la prefabricación porque ésta precisa el fraccionamiento de las vigas para su lanzamiento o colocación una a una. Esto es cierto en hormigón armado, no lo es tanto en estructuras metálicas y, desde luego, hay una compatibilidad completa en las soluciones de hormigón pretensado. El pretensado por fases tiene muchas posibilidades constructivas, permite crear nudos donde inicialmente sólo había apoyos, y en consecuencia, con los cambios de sustentación, podemos variar las leyes de momentos a nuestra conveniencia. Esta flexibilidad origina en obra una mayor economía que la que se deriva del empleo de materiales de mejores características que los clásicos en el hormigón.

La luz total de $45 \mathrm{~m}$, la dividimos en dos. Con el objeto de huir de las vías de la línea Madrid a Irún, la pila la acercaremos más hacia el Puerto, es decir, nos decidimos por la asimetría de luces, $28 \mathrm{~m}$ de luz por encima de RENFE, y $17 \mathrm{~m}$, la correspondiente a las vías del Puerto. Así conseguiremos, no solamente pasar por encima de las vías electrificadas en el lanzamiento de vigas, sino no producir molestias en éstas al cimentar la pila intermedia, precisamente por haberla separado de RENFE. Recordamos a este efecto que la cimentación de la pila (y lo mismo cabe hablar de los estribos) se ha proyectado a base de pilotes prefabricados in situ de $630 \mathrm{~mm}$ de diámetro y cimentados en la roca, que en esta zona aparece a unos $24 \mathrm{~m}$ de profundidad bajo la rasante de los muelles.

Se ha cuidado especialmente el aspecto estético del puente. Un buen efecto creemos que se ha conseguido con la curva suave y gradual del intradós de las vigas y la asimetría de vanos.

Así, pues, la estructura se ha conseguido de la siguiente forma: Una pila cimentada en roca y articulada en la base. Dos vanos de luz distinta y que estarán formados por vigas prefabricadas. Después del lanzamiento, las vigas apoyarán en los estribos y en la pila intermedia. En otra fase sucesiva se hormigonará el nudo de la cabeza de la pila, solidarizando, con ayuda del pretensado, las vigas de cada tramo con la pila. La estructura en $\mathrm{T}$ así resultante es hiperestática, ya que tiene, como soportes, la articulación en la base de la pila y dos apoyos, uno en cada estribo. Variando la tensión de los cables del pretensado conseguiremos despegar el vano corto de su apoyo, con lo cual las vigas de $17 \mathrm{~m}$ de luz quedan en voladizos, y la estructura pasa a ser isostática con unas leyes de momentos perfectamente determinadas. Sin embargo, este vano corto vuelve a apoyar en el estribo al paso de la sobrecarga, es decir, la estructura pasa a ser hiperestática solamente al paso del tráfico.

La razón por la que se ha huido del hiperestatismo para peso propio, es que es dudosa la proporcionalidad entre solicitaciones y giros, y es ésta la hipótesis fundamental para la determinación de las leyes de momentos. El método seguido es, en esencia, el de las desnivelaciones artificiales de apoyo, el cual se basa en que todo asiento produce una nueva distribución de momentos y modificando los asientos a voluntad se alteran las leyes para conseguir una distribución ideal. 


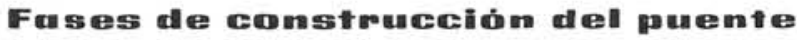

La figura 7 nos muestra un alzado del puente y una sección transversal. Las dovelas que forman las vigas tienen cantos variables: en el tramo de $28 \mathrm{~m}$ la variación es de $0,39 \mathrm{~m}$ a $1,51 \mathrm{~m}$, y en el tramo de $17 \mathrm{~m}$, de $0,75 \mathrm{~m}$ a 1,51 metros.

La figura 8 presenta un esquema de las distintas fases de construcción del puente y que describimos seguidamente:

\section{1. ${ }^{a}$ fase}

Esta fase no tiene por objeto más que solidarizar las distintas dovelas para formar las vigas con ellas, vigas cuyas longitudes son de $28 \mathrm{~m}$ unas y de $17 \mathrm{~m}$ otras. Para unir las dovelas, previamente a la prefabricación de las mismas, se han dejado unos cajetines en su interior para el paso de los alambres. Estos cajetines o huecos están en el alma de las dovelas, pero a distinta altura, según la posición de la dovela respecto a la viga. En el tramo largo se pasarán 52 alambres de $\varnothing 7 \mathrm{~mm}$, y en el tramo corto, solamente 24 alambres de $\varnothing 7 \mathrm{~mm}$. Simultáneamente se ha hormigonado la pila intermedia y se han dejado, en los paramentos, conductos para el paso de $60 \varnothing 7$ milímetros en uno de los costados y para $48 \varnothing 7 \mathrm{~mm}$ en el otro; todo ello por metro de anchura de pila, que es precisamente la separación entre ejes de vigas.

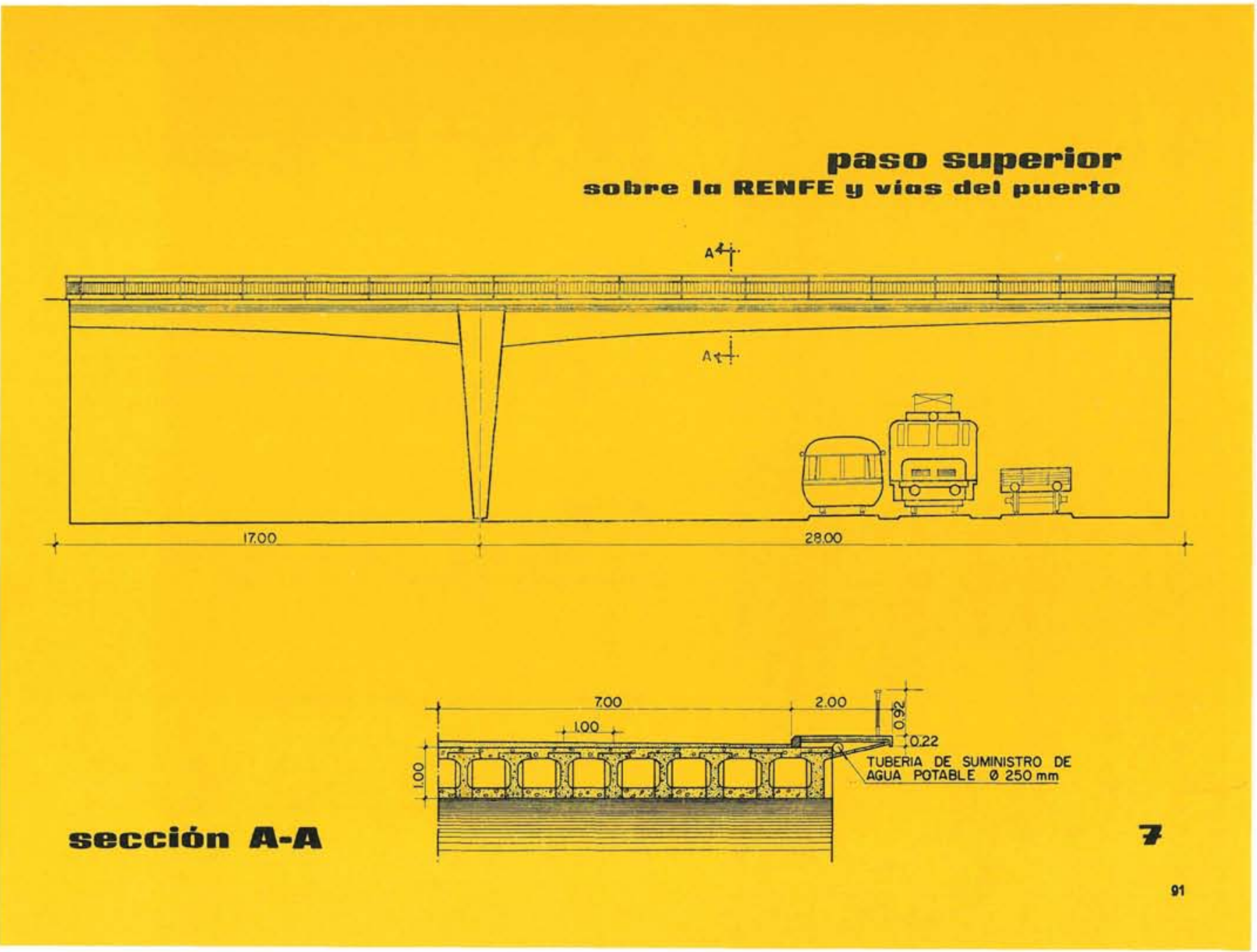




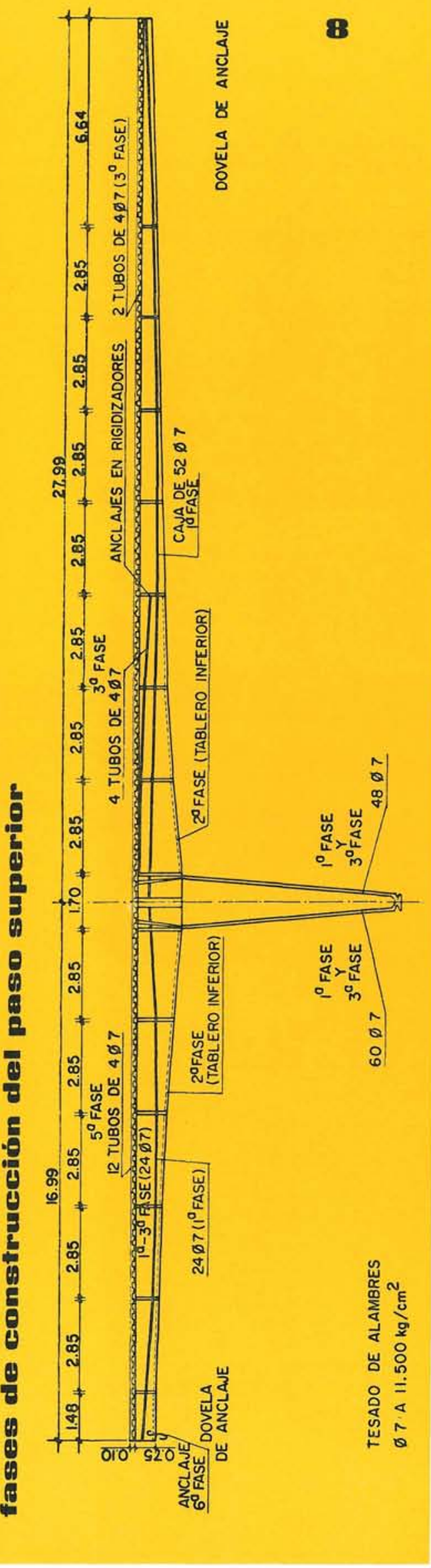

\section{2. ${ }^{a}$ fase}

Viene ahora el lanzamiento de las vigas. Las del tramo largo se han lanzado a través de un puente auxiliar, metálico, y que se montó encima del puente sobre la carretera. Las del tramo corto fueron colocadas con ayuda de una grúa. El lanzamiento de las vigas largas constituyó la parte más importante de la obra y se hizo con una circulación ferroviaria normal e ininterrumpida. Quedan ahora las 32 vigas (16 largas y 16 cortas) apoyadas en los estribos y en la pila. Se hormigona el tablero inferior en el tramo corto $\mathrm{y}$ en $\operatorname{los} 10 \mathrm{~m}$ de longitud del tramo largo.

\section{3. ${ }^{\text {a }}$ fase}

En esta fase se crea el nudo rígido en la cabeza de la pila, es decir, se solidarizan las extremidades de las vigas con la pila. Para ello se tesan las armaduras verticales de la pila en las dovelas extremas de los tramos. Seguidamente, por conductos dejados en la parte superior del tramo de $17 \mathrm{~m}$ se pasan 24 alambres de $\varnothing 7 \mathrm{~mm}$ (6 tubos para 4 alambres cada uno). Estos 24 alambres pasan al tramo largo, de ellos 8 en toda la longitud y los 16 restantes en unos $10 \mathrm{~m}$ de longitud aproximadamente. A continuación se hormigona la junta sobre la pila y seguidamente se procede al tesado de los alambres.

\section{4. ${ }^{a}$ fase}

Solidarizados los tramos del puente y de la pila se deja el extremo del tramo de $17 \mathrm{~m}$ en voladizo, suprimiendo su apoyo, con lo cual se obtiene una estructura isostática para peso propio.

\section{5. ${ }^{a}$ fase}

Se ejecuta el tablero superior en todo el tramo corto y en unos $12 \mathrm{~m}$ de longitud del tramo largo. En el hormigonado se tendrá la precaución de dejar 12 conductos para el paso posterior de 48 alambres de $\varnothing 7 \mathrm{~mm}$. Se pasan los alambres y se tesan. Seguidamente se termina la construcción de este tablero en el resto del tramo largo.

\section{6." fase}

Se termina el puente. Se solidariza, mediante una biela, el estribo con la extremidad del tramo corto.

\section{Comstructéióm del puente}

La explicación será somera, puesto que remitimos al lector a los planos y fotografías adjuntos, los cuales trataremos de comentar por el mismo orden con que se realizaron las obras. 


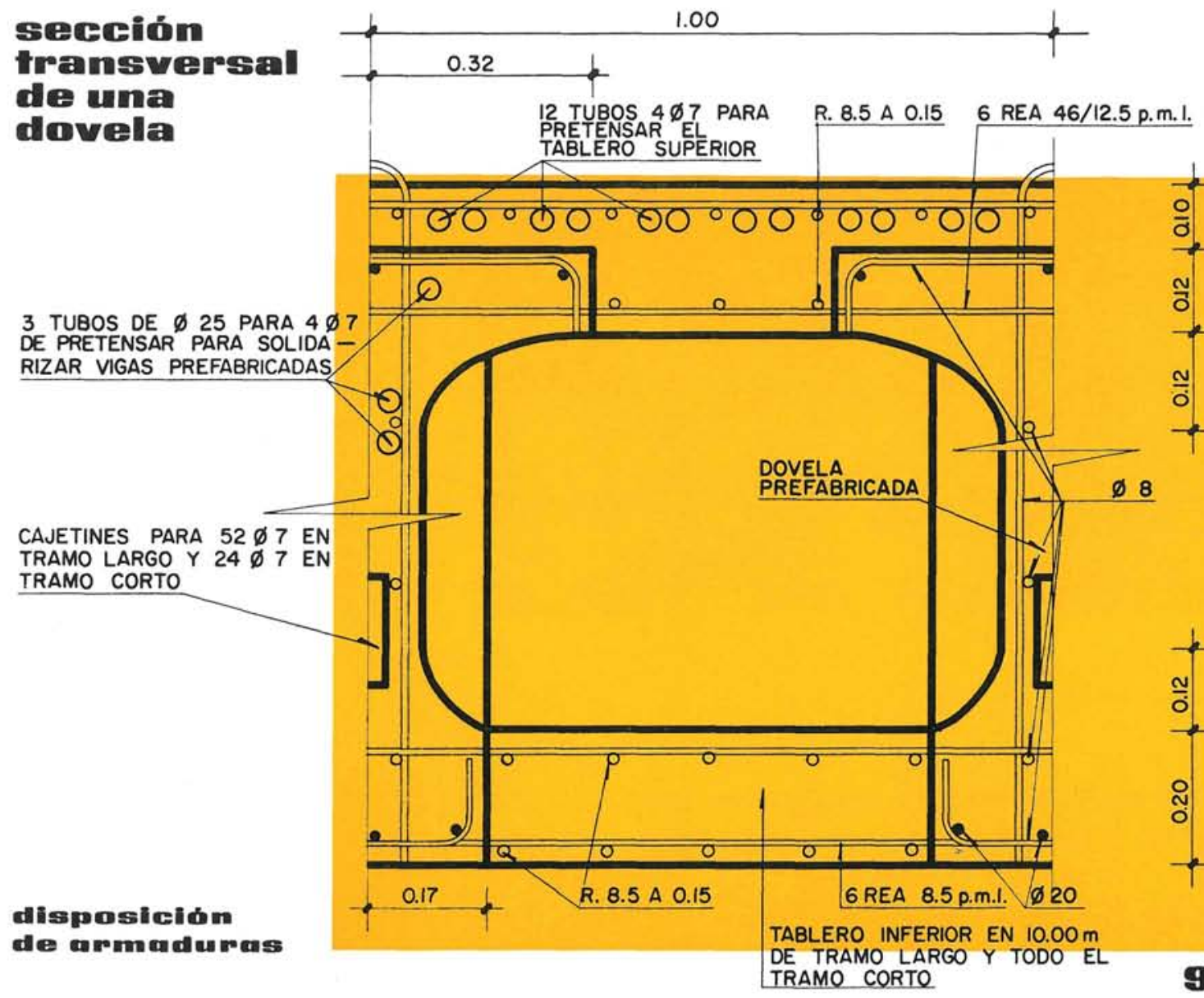

En la figura 9 copiamos la sección transversal de una dovela, en la que pueden observarse los distintos huecos dejados para el paso de cables. En la parte inferior se ha dejado el cajetín para el tesado de la 1." fase. En la parte superior de la dovela aparecen los tubos para el paso de alambres tesados en la 3." fase. Finalmente, en el tablero superior figuran los tubos de los alambres tesados en la 5." fase.

Las dovelas se presentan en obra para la formación de vigas. Los cajetines en las dovelas contiguas deben estar enfrentados para el paso de cables. Entre cada dos dovelas se coloca un taco guía para mantener una separación correcta entre alambres (fig. 10).

\section{1}

Presentación de las dovelas con los cajetines y tubos enfrentados para el pas del acero especial.

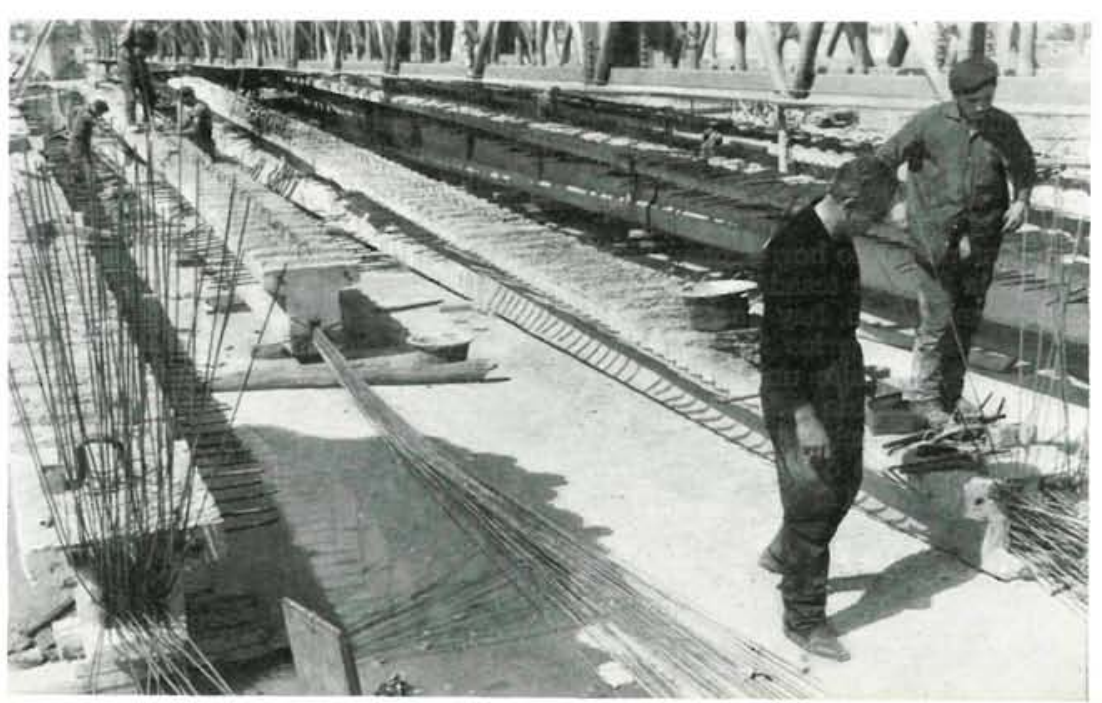




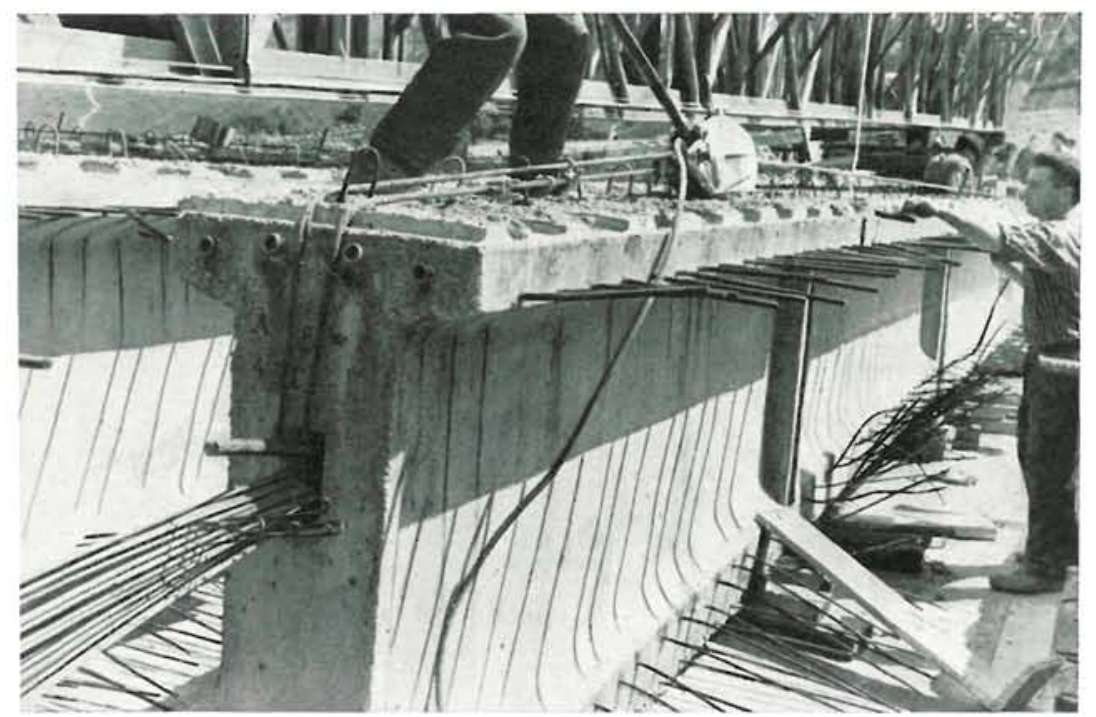

11

Ajuste y alineación en posición de las dovelas para formar la viga. Detalle de unión entre dovelas.

Para formar las vigas todavía hay que alinear correctamente en posición las dovelas y esto se hace con ayuda de un tractel (fig. 11). Hay que esmerarse en las operaciones a fin de no estropear el paramento visto de las vigas y cuidar especialmente las aristas para que no se desportillen.

Colocadas las dovelas en posición y, antes del hormigonado de las juntas, se coloca un tubo vertical para la inyección de la papilla de cemento al interior de los cajetines (fase $1 .{ }^{2}$ ). Igualmente hay que colocar unos manguitos que aseguren la continuidad de los tubos para el paso de los alambres (fase 3."). En la figura 12 pueden observarse estos detalles.

En este momento se hormigonan las juntas entre dovelas. Ahora viene la fase de tesado de cables; pero previamente, como se tesan uno a uno, hay que separarlos de forma que el gato pueda después cogerlos aisladamente y con comodidad. Esto se consigue mediante unos tacos guía de 4 orificios (fig. 13) que se colocan en la extremidad de la dovela de anclaje. En esta dovela se observa que el cajetín de las dovelas intermedias, al llegar a la de anclaje, se transforma en una serie de orificios distintos (13 en nuestro caso) para repartir los esfuerzos del tesado.
Viene ahora la aplicación de los gatos para dar a cada alambre una tensión de $11.500 \mathrm{~kg} / \mathrm{cm}^{2}$. El gato se presenta sobre un alambre. La cuña que encaja en el taco deja suelto al alambre. En la parte posterior del gato se coloca un taco cilíndrico, que mediante una cuña sujetará el alaınbre. En la figura 14 se ven, de forma clara, los elementos descritos. El equipo es sencillo y cómodo para su aplicación (fig. 15).

Tesados los cables se inyecta la papilla que llena el interior de los cajetines, y ya están las vigas formadas y dispuestas para su colocación. Se montó un puente auxiliar de lanzamiento constituido por piezas metálicas en celosía. Como al principio de los

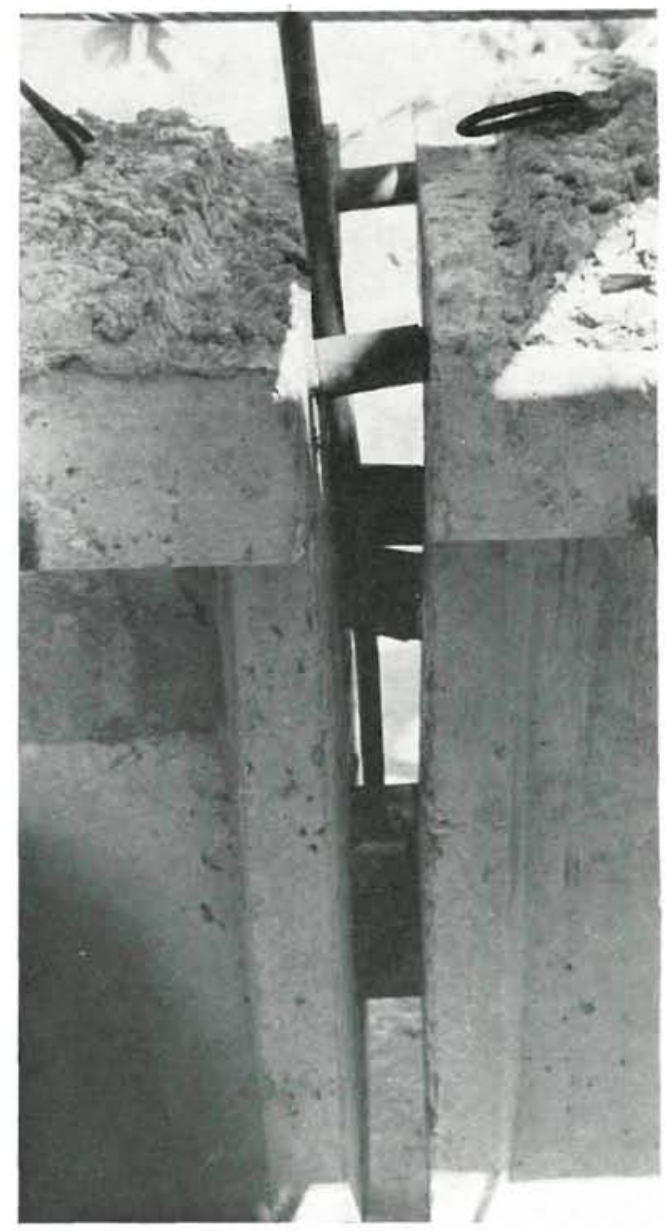




\section{3}

Pasando los alambres para formar una viga.

\section{4.}

Tesando los alambres: cada alam bre recibe una tensión de $4.450 \mathrm{~kg}$. equivalentes a la unitaria de 11.50 ogramos $/ \mathrm{cm}^{2}$

Momento en el que se da tensión al alambre.
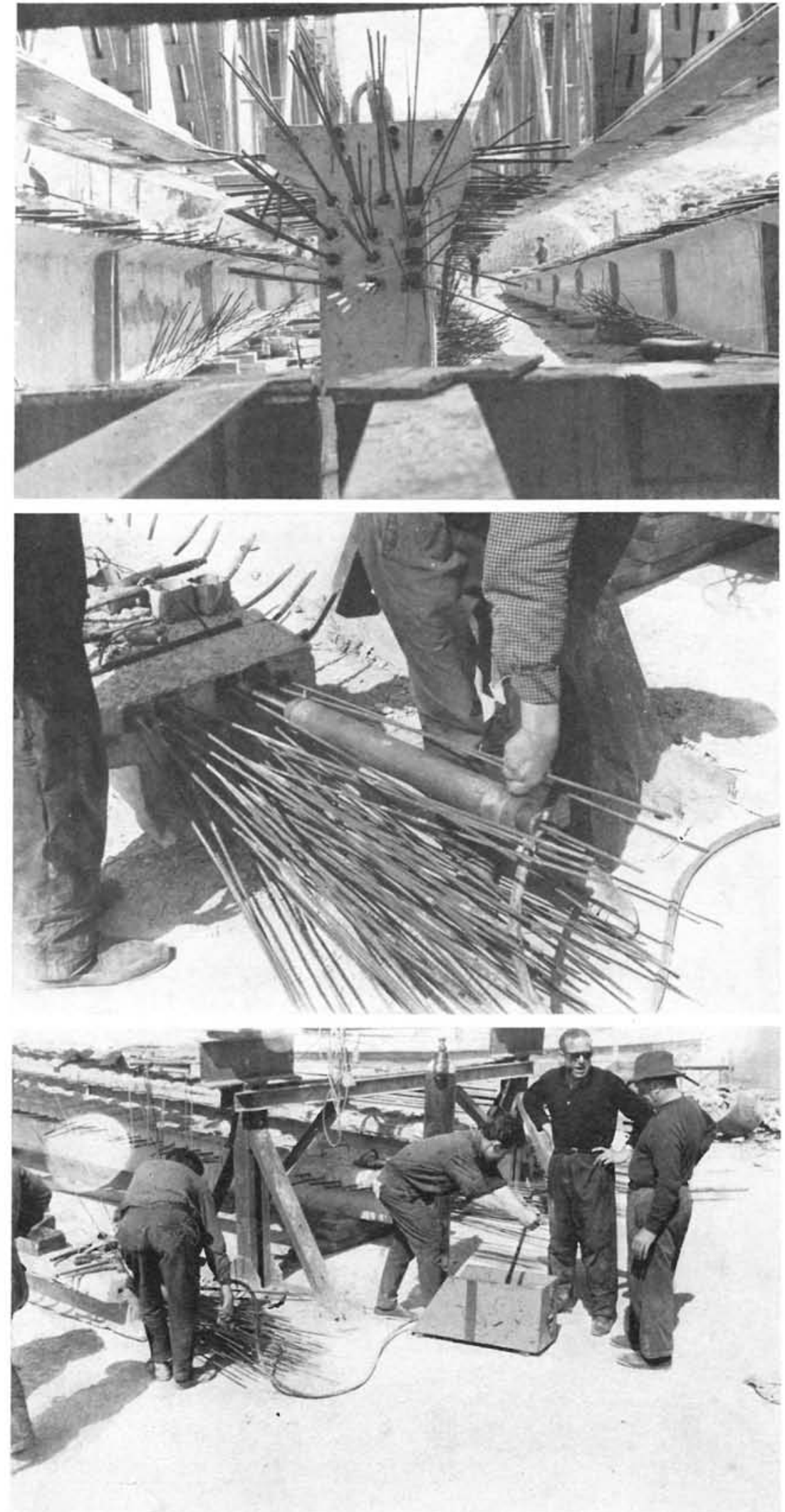


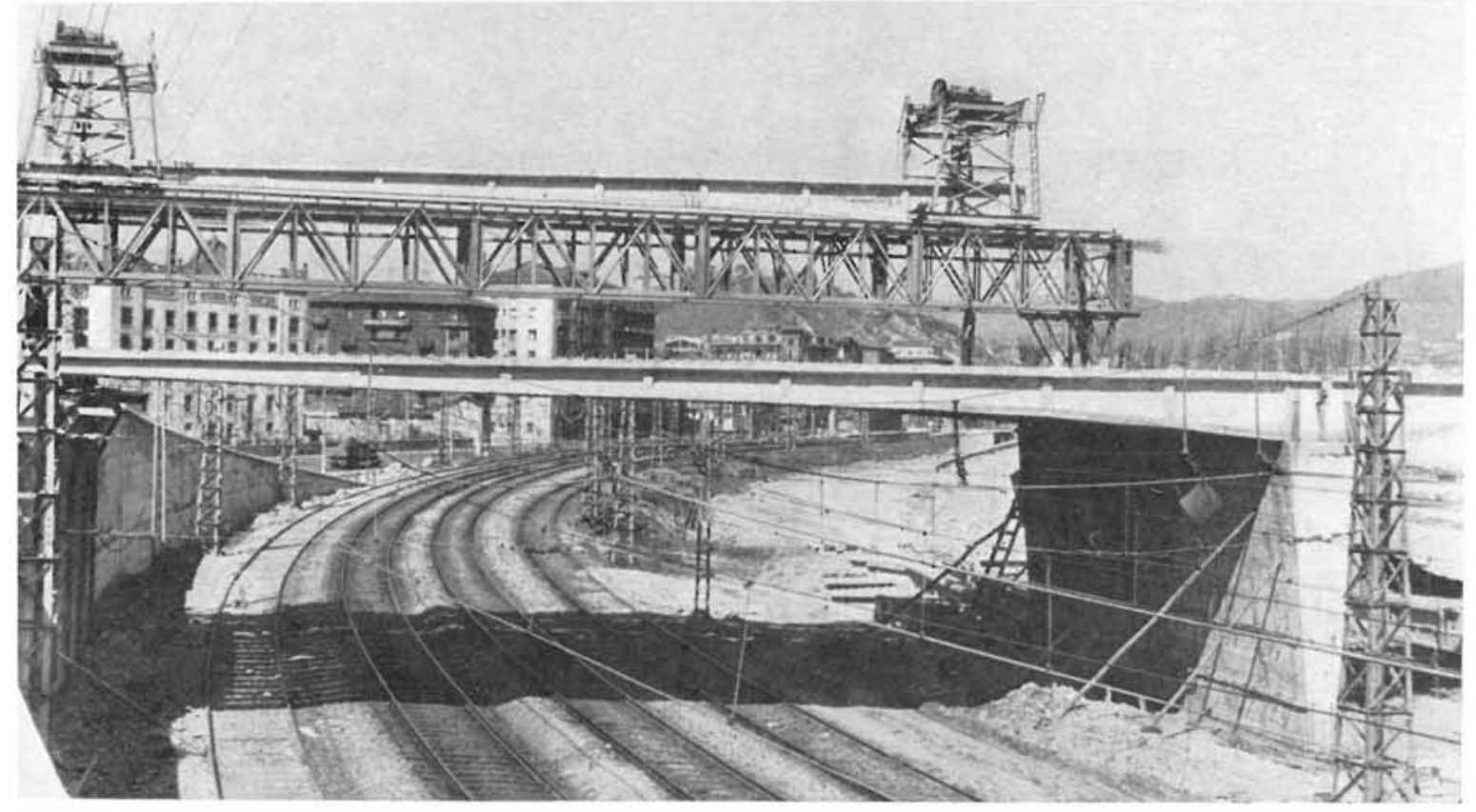

11 Puente de lanzamiento transportando una viga de $28 \mathrm{~m}$ a su emplazamiento: la longitud de este puente auxiliar es de 60 metros.

trabajos el puente tiene que volar y avanzar hasta descansar en la pila, con el mismo alambre del pretensado se hicieron unos cordones para su colocación en la horizontal superior de la estructura. Estos cables se tesaron, y contrarrestaron de esta forma el trabajo en voladizo. Una vez que el puente apoyó en la pila, mejoraba su sistema de trabajo y permitía la colocación de dos carretones móviles en la parte superior. De los carretones colgaban las vigas de $28 \mathrm{~m}$ que las transportaban al emplazamiento definitivo (figs. 16 y 17). La colocación de las vigas cortas se hizo directamente con una grúa auxiliar, al no existir ningún tendido de vías (fig. 18). Hasta aquí llegamos al final de lo que hemos denominado como fase 2..

Perspectiva del tramo de $28 \mathrm{~m} \mathrm{y}$ de la pila intermedia: pueden observarse los alambres en la cabeza de la pila, con los que posteriormente se efectuará la unión a los tramos de 28 y de $17 \mathrm{~m}$ respectivamente, formando un nudo rígido.

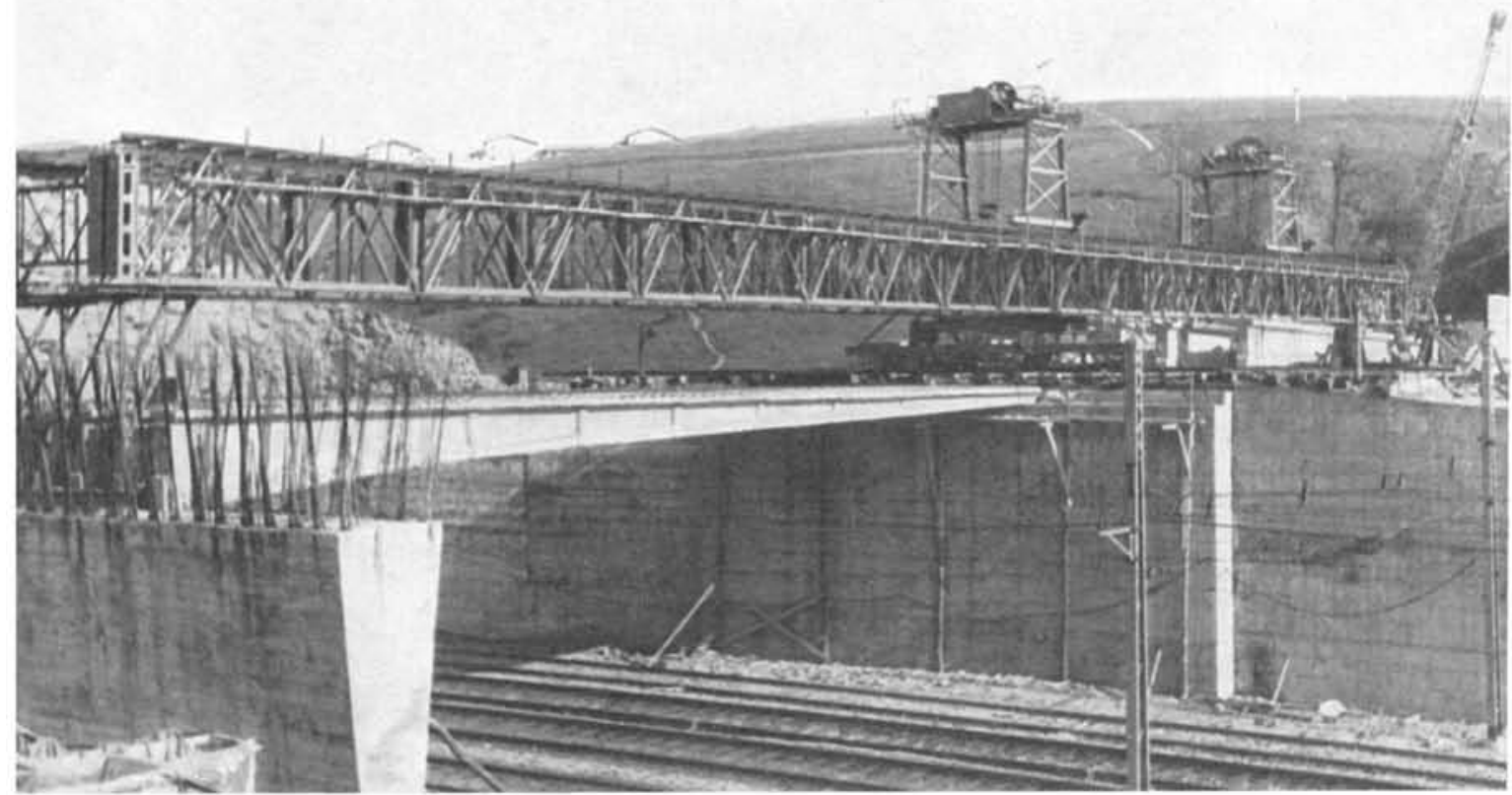



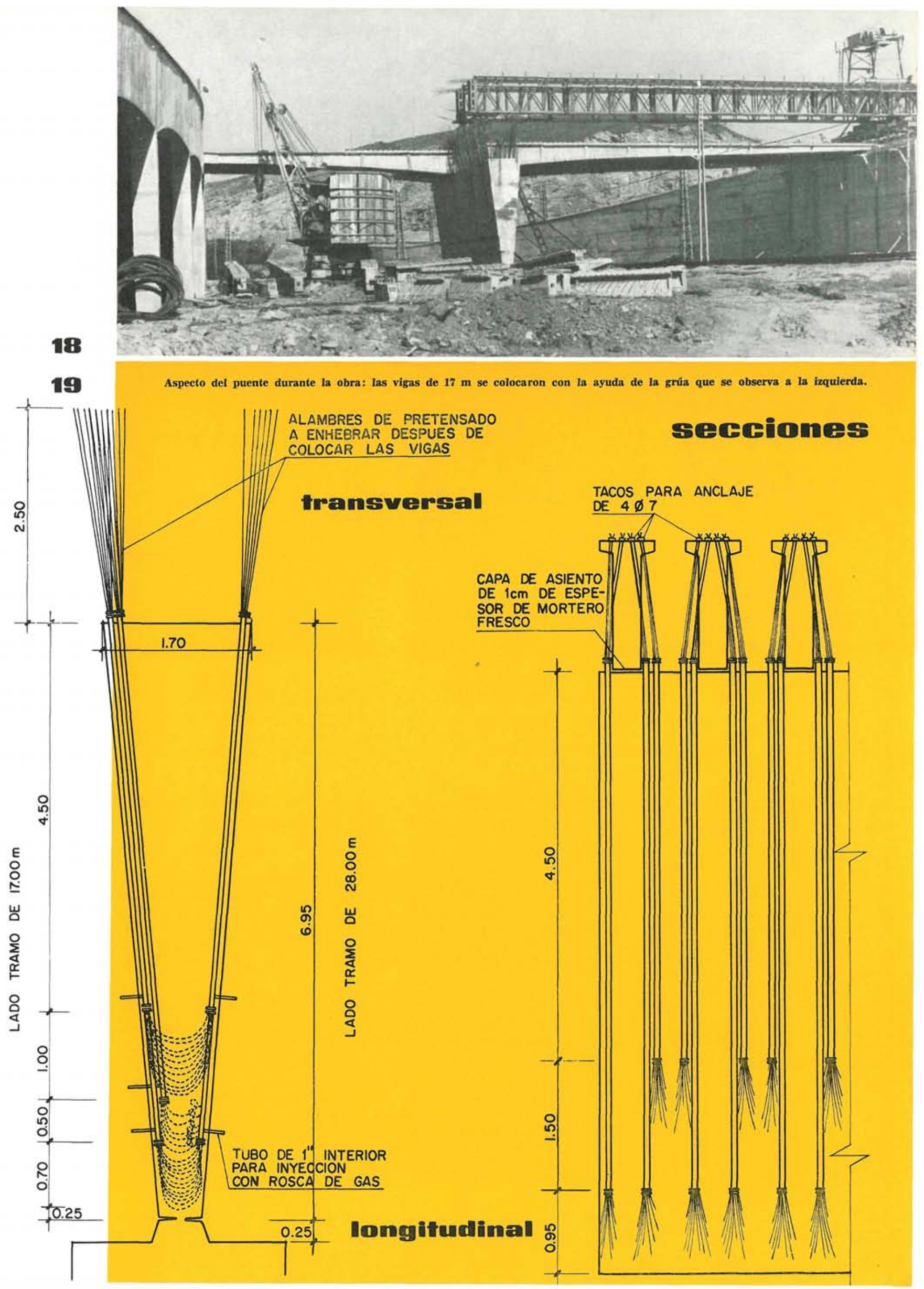

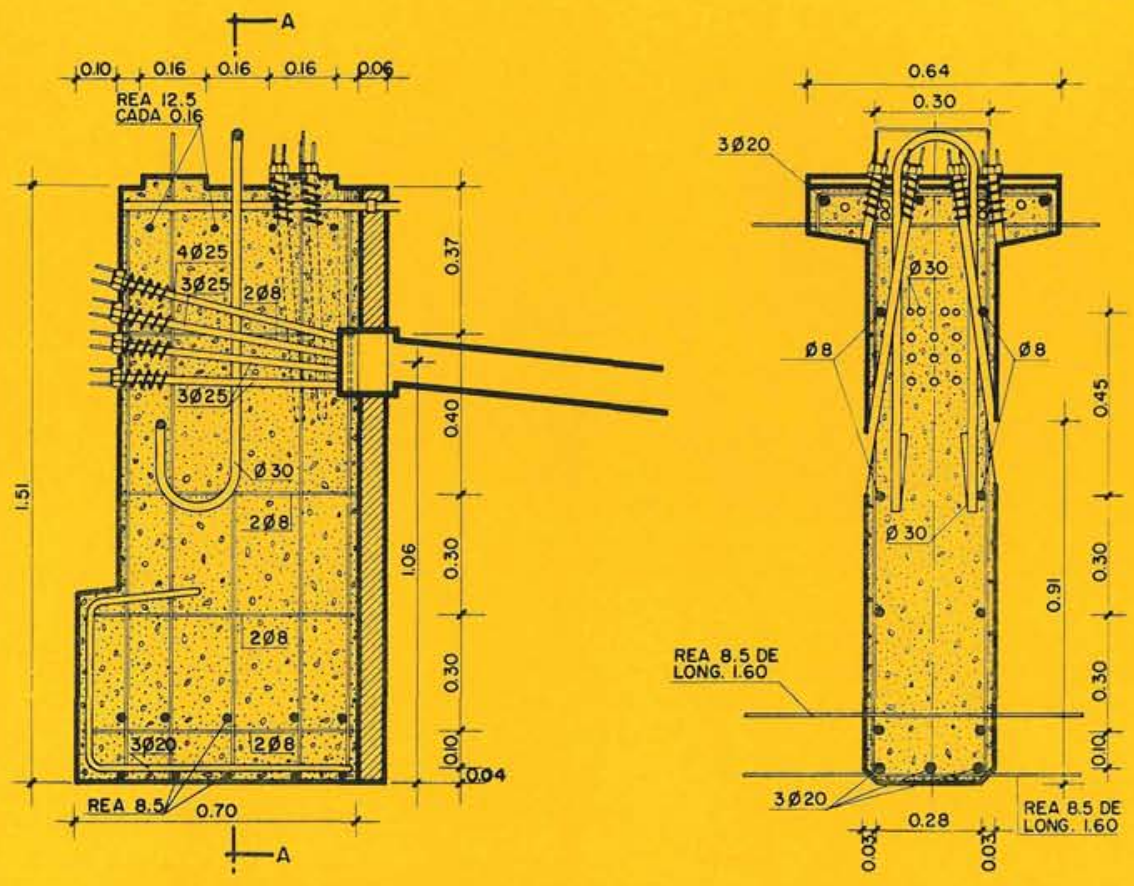

sección A-A
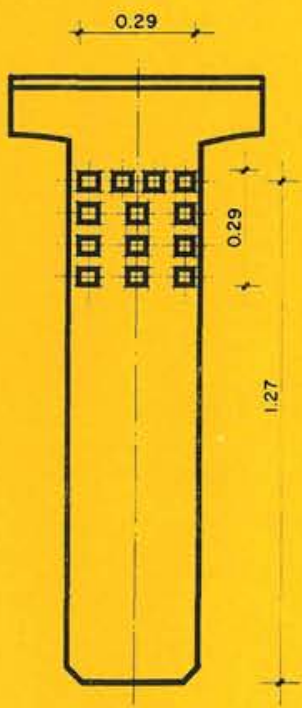

dovella die anclaje

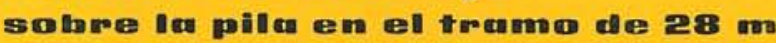

El comienzo de la 3." fase consiste en la creación del nudo en la cabeza de la pila. Hemos acompañado un plano (fig. 19) con el detalle de las armaduras de la pila y el anclaje a las dovelas de extremidad. En este plano podemos observar que para anclar un alambre basta que siga una trayectoria en espiral, y por rozamiento contra el hormigón se consigue el anclaje deseado. Dentro de los tubos de los paramentos de la pila hay que colocar unas rejillas separadoras, con objeto de que los alambres no se amontonen en un mismo costado, sino que vayan equidistantemente repartidos por el interior de los tubos. La figura 20 presenta el detalle de la dovela de anclaje a la pila correspondiente al vano de $28 \mathrm{~m}$. En el vano corto hay otra dovela parecida. En este detalle se observa: la conversión del cajetín en varios tubos para el tesado de la $10^{\mathrm{a}}$ fase, los conductos horizontales en el alma de la dovela para el tesado de la fase $3 .^{z} \mathrm{y}$, finalmente, los conductos con una fuerte inclinación (casi verticales) para el paso de los alambres de la pila y su tesado posterior sobre el ala de la dovela.

\section{Finga!}

Creemos haber explicado las partes más importantes de la obra; el resto de ella no reviste tanto interés. Los firmes fueron proyectados como firmes flexibles y de acuerdo con las instrucciones vigentes para los mismos, a base de explanada mejorada, sub-base, base y capa de aglomerado. Se completó la obra con una iluminación adecuada y con jardinería en la zona central del bucle y en el triángulo del mismo, y con todo ello la obra ha ganado de aspecto y se ha conseguido un conjunto muy logrado que los extranjeros, en su visita a España, se encuentran a pocos kilómetros de la frontera Irún-Behobia. 

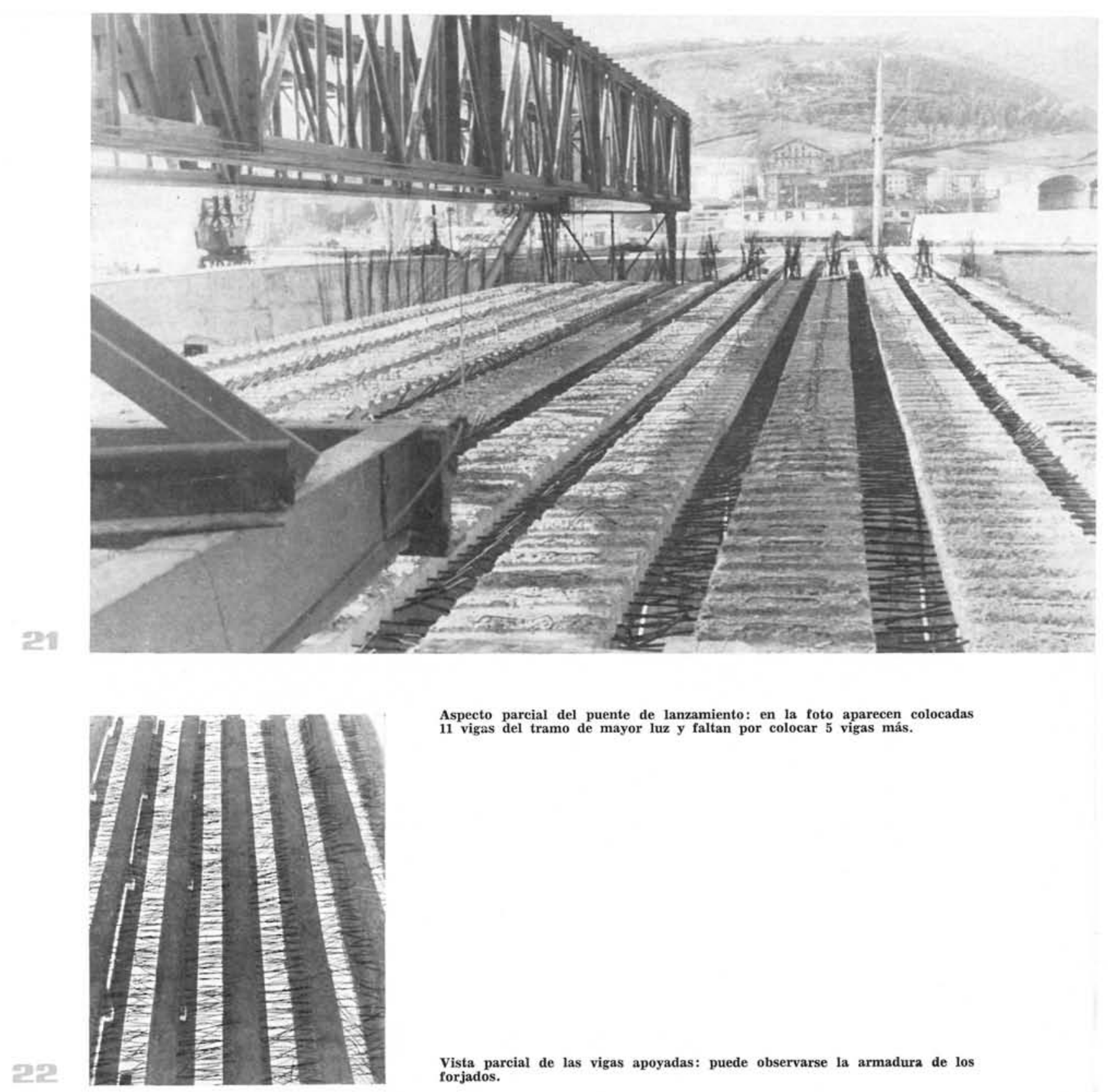

Aspecto parcial del puente de lanzamiento: en la foto aparecen colocadas 11 vigas del tramo de mayor luz y faltan por colocar 5 vigas más. Vista parcial de las vigas apoyadas: puede observarse la armadura de los
forjados.

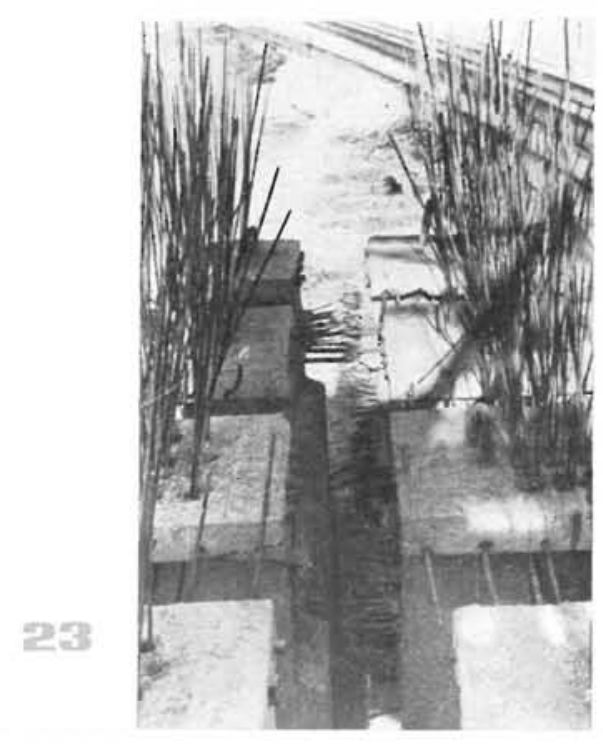

Detalle del anclaje de los tramos a la pila intermedia. 
En un principıo se proyectó un puente sobre las vías de RENFE y del Puerto de mayor luz total, con una separación de estribos de $60 \mathrm{~m}$ y una solución de hormigón armado con dos pilas intermedias. Este primitivo proyecto fue redactado por el autor de este artículo. Posteriormente y, como consecuencia de unos estudios de trazados de vías realizados conjuntamente con RENFE, se vio que podía reducirse la playa de vías de clasificación y maniobra y que también podía acortarse la separación de estribos a $45 \mathrm{~m}$, con la evidente ventaja que suponía para la explotación del puerto disponer de una mayor zona de servicio junto a los muelles. Este nuevo puente que sustituía al anterior es el que hemos descrito y fue proyecto de nuestro compañero Alfredo Páez, maestro de todos en hormigón y que en aquel entonces era Director de la oficina de proyectos de Hidrocivil.

La obra fue realizada por la Cía. de Construcciones Hidráulicas y Civiles (HIDROCIVIL), excepto la cimentación por pilotaje, que corrió a cargo de Cimentaciones Rodio. Es una satisfacción para el autor de este artículo manifestar la precisión y maestría con que Hidrocivil llevó a cabo el puente pretensado. Y un recuerdo en estas líneas a todos los colaboradores de la obra y del proyecto, con una mención especial a los encargados de obra (de la Junta de Obras y de Hidrocivil) que con su labor diaria tanto han facilitado esta realización.

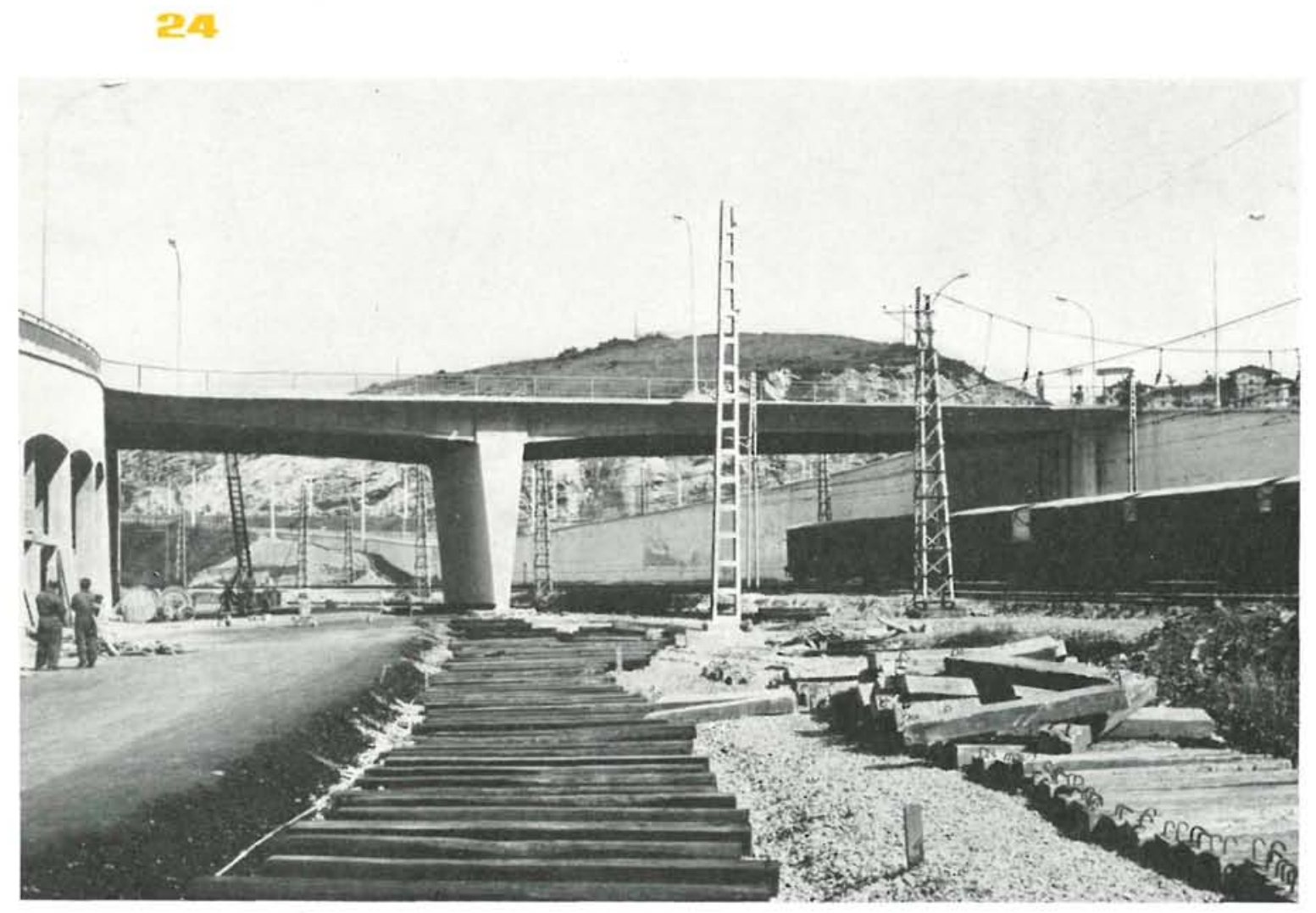

Aspecto general del puente, una vez terminado. 


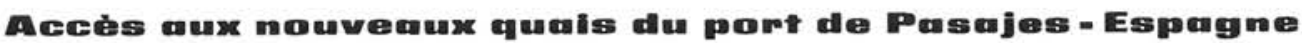

Carlos Martínez Cebolla, Dr. ingénieur

Cet article présente l'ouvrage des accès aux nouveaux quais du port de Pasajes. Ces accès ont pour but de faciliter le passage, au-dessus des voies ferrées, des véhicules regagnant ou quittant les quais. En plus, ce passage ne cause aucune interruption à la circulation routière sur la nationale N-1 Madrid-Irun. Son esthétique et son caractère fonctionnel seront hautement appréciés par les usagers du port et même par les touristes étrangers venant de la frontière Irun-Béhobie, distante de peu de kilomètres de cet ouvrage. Mais le motif principal de cet article a été la description de la solution de précontrainte donnée à l'un des ponts. C'est l'un des premiers ouvrages de ce type exécutés en Espagne, bien que, logiquement, ce soit sous peu un type d'ouvrage courant, précisément pour le besoin qu'on en a. L'ouvrage a été inauguré le 28 mars 1966 par le Ministre espagnol des Travaux publics.

\section{Entrg to the mew wharues at Pascujes Harbour, Spain}

Carlos Martínez Cebolla, Dr. engineer

This article describes the entry to the new wharves at Pasajes Harbour. This access route provides a means of entry of vehicles to the wharves, passing over the railway lines, and over the main N-1 national Madrid to Irun highway. The efficiency of this arrangement will be highly appreciated by the users of the harbour, and by foreign tourists, since Pasajes is close to the Irun-Behobia frontier.

But the main purpose of this article is to describe the method of prestressing of one of the bridges involved in this project. It is one of the first applications of this system in Spain, though it is likely to become very widely used, due to its general efficiency. This project was inaugurated by the Minister of Public Works on March 28, 1966.

\section{Zugang zu den meuen Quaiumlagen in Postajeshafen - Spanien}

Carlos Martínez Cebolla, Dr. Ingenieur

Im vorliegenden Artikeln weist man den Bau der Zugänge zu den neuen Quaianlagen in Pasajes. Diese Zugänge wurden mit dem Zweck gebaut, die Einfahrt und die Ausfahrt von Fahrzeugen zu den Quaianlagen über der Eisenbahn und dem Hafen zu erlauben und ohne der Verkehr auf der Nationalstrasse Nr. 1 von Madrid nach Irun zu stören. Seine Esthetique und seiner Betrieb werden von den Benutzern des Hafens und den Ausländern bewert werden, da er sich wenig $\mathrm{Km}$. von der Grenze Irun-Behobia befindet. Aber der Leitgedanke des Artikels ist die Beschreibung der Vorsspannung von einer der Brücken. Es ist einen der ersten Baue in Spanien von diesem Typ. In einigen Jahren wird dieser Typ von Bauen ganz üblich sein, wegen seiner Nützlichkeit. 